\title{
Introduction to Technologies in the Daily Lives of Individuals with Autism
}

\author{
Frederick Shic ${ }^{1} \cdot$ Matthew Goodwin ${ }^{2}$
}

Published online: 3 November 2015

(c) Springer Science+Business Media New York 2015

\begin{abstract}
In this introduction to the Special Issue on Technology we explore the continued evolution of technologies designed to help individuals with autism. Through review articles, empirical reports, and perspectives, we examine how far the field has come and how much further we still can go. Notably, even as we highlight the continuing need for larger empirical studies of autism-focused technology, we note how improvements in the portability, sophistication, ubiquity, and reach of daily technologies are providing new opportunities for research, education, enhancement, knowledge, and inspiration. We conclude by discussing how the next generation of technologies may leverage the increasing promise of big-data approaches to move us towards a future where technology is more personal, more relevant, and pervasively transformative.
\end{abstract}

Keywords Technology Robots - Games · Apps ·

Mobile · Computers · Ubiquitous computing

Recent trends in technology usage suggest our lives are becoming increasingly interconnected as our access to mobile technologies, information networks, and social media grows (Raine 2014). In addition, advances in the

Frederick Shic

frederick.shic@yale.edu

Matthew Goodwin

m.goodwin@neu.edu

1 Yale Child Study Center, School of Medicine, Yale University, 40 Temple St Suite 7D, New Haven, CT 06510, USA

2 Department of Health Sciences, College of Computer and Information Science, Northeastern University, 312E Robinson Hall, 360 Huntington Ave, Boston, MA 02115, USA development of innovative technological tools and our increasing sophistication regarding their use continues to provide novel supports, educational opportunities, and inspiration for our daily lives. These trends similarly impact the lives of individuals with autism spectrum disorders (ASD), their teachers, and their families. This special issue has been created to highlight this impact.

Our issue begins with a series of reviews and perspectives (Lorah et al. 2015; McCleery 2015; Odom et al. 2015; Stephenson and Limbrick 2015; Whyte et al. 2015) which add to our knowledge about trends in technologies for autism research and clinical practice (e.g. see Grynszpan et al. 2014; Kientz et al. 2013; Boser et al. 2013). Stephenson and Limbrick (2015) report on advances in the use of mobile technologies by individuals with disabilities, highlighting the enormous potential of these devices while providing a realistic perspective on critical needs in mobile technology research, such as larger, well-designed research projects and a broader exploration of mobile software applications used for education. Lorah et al. (2015) provide a focused review on tablet and portable media players used as speech-generating devices for individuals with ASD. In their review, they note that while these systems appear to be both effective for and appreciated by the students who use them, success depends as much on the training protocols used as it does on hardware or software, and warn against mistaking "the device for the process." Odom et al. (2015) apply the Persuasive Technology perspective under the CSESA technology conceptual framework (which considers the user, the activity to be supported, and the technology) to 30 high-quality studies, concluding that extant research supports the use of technology for instruction and intervention for adolescents with ASD. The authors end their review by emphasizing the need for technology research to translate findings into practice, 
considering generalization in multiple contexts and practical goal attainment as priorities. Along this line, Whyte et al. (2015) highlight the difficulties individuals with ASD experience in generalizing skills learned through computerassisted instruction and "serious games", and follow by offering detailed guidance to future developers of such systems based on serious game design principles. Joseph McCleery (2015) then provides a synthesizing meta-review, identifying further areas to be addressed by research and future opportunities for improving dissemination of technological progress into the wider world. Continuing this theme, this meta-review is followed by a letter discussing the role of small business funding and researchbusiness partnerships in catalyzing the transformation of technological innovation into real-world impact (Shic et al. 2015).

Additional contributions in this issue provide a window into the vast array of technological innovations that are rapidly beginning to find a role in the daily lives of individuals with ASD. Macpherson et al. (2015) use a tabletbased video modeling intervention to increase the verbal compliment behaviors made by children with ASD during athletic games, highlighting the potential for handheld technologies to effect behavior change in children with ASD during naturally occurring social events. Spriggs et al. (2015) similarly use video modeling on a tablet, but embed it within a visual activity schedule in order to provide educational opportunities and foster independence. The results of this study suggest that portable video modeling and visual supports are effective for teaching academic, vocational, and daily-living skills, evidenced by the students' demonstrated high rates of generalization of learned skills and improvement in independent transitions between activities. These studies are only a few examples of the many new applications and variations on older themes made possible by the increasing ubiquity of mobile technologies.

The work of Kaboski et al. (2015) and Warren et al. (2015) highlight the increasing capabilities, sophistication, and varied multi-disciplinary applications of social robots for addressing educational and interventional goals for children with and without ASD (Kim et al. 2012; Scassellati et al. 2012). Specifically, Kaboski et al. (2015) shows how a novel intervention based on a robotics summer camp for children with ASD and their typically developing peers mitigates social anxiety in children with ASD. This study also highlights opportunities to use robots and other novel technologies as platforms for creating shared experiences between children with ASD and others. The work of Warren et al. (2015) pairs a Microsoft Kinect with a commercially-available robot in order to create a system for examining imitation skills in children with ASD. This system represents a new breed of robotic platforms that are "closed-loop," i.e., capable of responding dynamically in real-time under autonomous guidance as compared to being controlled remotely or executing highly constrained pre-programmed scripts. This study also underscores the enhanced compliance and response of some children with ASD to social robots.

Wainer and Ingersoll (2015) use a hybrid telehealth program to teach an imitation intervention to parents of children with ASD. The results of this study suggest that a telemedicine intervention approach is feasible, acceptable, and especially effective for some parents, providing greater support for the hope that such an approach could be applied to deliver interventions to areas with limited services or supports for families in need. Rice et al. (2015) examine the effects of a video game program targeting face processing skills in school-age children with ASD and find that training not only improves affect recognition skills, but also social behavior as rated by a teacher, and potentially more distal theory of mind skills. This study highlights the potential for semi-automated systems to affect behaviors and foster skill acquisition, as well as underscoring the utility of broader monitoring for examining generalization even within more narrowly defined instructional areas. In a study by Kim et al. (2015), a joy stick is used to virtually control the distance between the observer and an avatar displaying one of six emotional expressions. In contrast to other recent virtual reality work examining therapeutic or educational aspects of virtual reality (e.g. Bekele et al. 2014; Smith et al. 2015), Kim et al. (2015) examine how technological platforms may provide additional insights regarding phenotypic variation at the group or individual level. This last area, that of the exceptional monitoring and dense data collection capabilities of many technological platforms, is especially topical as it can often be overshadowed by a singular focus on therapeutic outcomes.

Technology work in autism research is expanding at a breathtaking pace. Not only are we gaining a more nuanced understanding of the impact technology can have on the lives of individuals with ASD, we are also gaining a deeper understanding of these technologies at a fundamental level. More and more, we are using these technologies to refine our understanding of the autism spectrum itself. From the laboratory to the clinic, to the daily lives of individuals on the spectrum, the new era of technology development in autism research may very well be defined by the massive volume and mind-boggling complexity of dense technology-acquired metrics of behavior. To manage such information streams, we will need to look carefully towards more powerful statistical and data mining approaches such as those highlighted by Bone et al. (2014). However, as noted by Bone et al. (2014), perhaps even more important than access to the right machine learning algorithms in this next evolution of technology will be the right perspectives, 
representing knowledge of where collected data comes from, what it means, and how it can be realistically used in practice.

In this special issue we can see the increasing sophistication of the field; the transformation of technology research for ASD from theoretical novelties into tools that are better understood, more solidly studied, more nuanced, and more practically relevant. But, as Lorah et al. (2015) note, it is indeed a folly to "mistake the device for the process." As the capabilities of our technology grow, so too will the stakes. Every generation of advancement comes with its own litter of glamorous falsehoods and untenable promises. One would hope that such endeavors are self-correcting and leave only a legacy of lessons learned.

In the end, to fulfill the promise of technology research for individuals with ASD, it will be necessary to focus on process and outcomes. Such an approach is already in play, as evidenced by the formidable multidisciplinary science showcased here. While the future of autism-focused technologies is unpredictable and complex, it is almost assuredly one that combines the very best of our collective insights: from the technologists, to the clinicians, to the data miners, to the biomedical researchers, to the educators, to the students, to the business funders, to the businesses, and to everyone with a stake in building a better future for individuals affected with autism and other developmental issues.

Acknowledgments The authors would like to thank Logan Hart, Yeo Jin Ahn, Erin Barney, and Claire Foster for their helpful edits. Funding for FS contributing to perspectives in this article include: NIH K01 MH104739, R21 MH103550, R21 MH102572, CTSA Grant Number UL1 RR024139; Department of Education IES EDIES13C0046 I and II; NSF Expedition in Socially Assistive Robotics \#1139078; and the Simons Foundation for Autism Research Initiative. Funding for MG includes: NIH Grant \#1P50DC013027, NSF grant Expedition in Computational Behavioral Science \#CCF1029585, and the Simons Foundation for Autism Research Initiative. Views in this paper reflect the perspectives and opinions of the authors and not necessarily those of any funding agency.

Authors' Contributions FS and MG organized and edited this special issue and wrote this commentary.

\section{Compliance with Ethical Standards}

Conflict of interest Frederick Shic has received research funding from F. Hoffmann-La Roche AG, and Janssen Pharmaceutica, LLC. Matthew Goodwin has COIs arising from work with Janssen Pharmaceutica, LLC, Affectiva, Inc., Empatica, Inc., and Behavior Imaging Solutions, Inc.

\section{References}

Bekele, E., Crittendon, J., Zheng, Z., Swanson, A., Weitlauf, A., Warren, Z., \& Sarkar, N. (2014). Assessing the utility of a virtual environment for enhancing facial affect recognition in adolescents with autism. Journal of Autism and Developmental Disorders, 44(7), 1641-1650. doi:10.1007/s10803-014-2035-8.

Bone, D., Goodwin, M. S., Black, M. P., Lee, C.-C., Audhkhasi, K., \& Narayanan, S. (2014). Applying machine learning to facilitate autism diagnostics: Pitfalls and promises. Journal of Autism and Developmental Disorders, 45(5), 1121-1136. doi:10.1007/ s10803-014-2268-6.

Boser, K. I., Goodwin, M. S., \& Wayland, S. C. (2013). Technology tools for students with autism: Innovations that enhance independence and learning. Baltimore, MD: Brookes Publishing Company.

Grynszpan, O., Weiss, P. L. T., Perez-Diaz, F., \& Gal, E. (2014). Innovative technology-based interventions for autism spectrum disorders: A meta-analysis. Autism, 18(4), 346-361. doi:10. 1177/1362361313476767.

Kaboski, J. R., Diehl, J. J., Beriont, J., Crowell, C. R., Villano, M., Wier, K., \& Tang, K. (2015). Brief report: A pilot summer robotics camp to reduce social anxiety and improve social/ vocational skills in adolescents with ASD. Journal of Autism and Developmental Disorders, 45(12). doi:10.1007/s10803-0142153-3.

Kientz, J. A., Goodwin, M. S., Hayes, G. R., \& Abowd, G. D. (2013). Interactive Technologies for Autism. Synthesis lectures on assistive, rehabilitative, and health-preserving technologies, 2(2), 1-177. doi:10.2200/S00533ED1V01Y201309ARH004.

Kim, E. S., Paul, R., Shic, F., \& Scassellati, B. (2012). Bridging the research gap: Making HRI useful to individuals with autism. Journal of Human-Robot Interaction, doi:10.5898/jhri.v1i1.25.

Kim, K., Rosenthal, M. Z., Gwaltney, M., Jarrold, W., Hatt, N., McIntyre, N., et al. (2015). A virtual joy-stick study of emotional responses and social motivation in children with autism spectrum disorder. Journal of Autism and Developmental Disorders, 45(12). doi:10.1007/s10803-014-2036-7.

Lorah, E. R., Parnell, A., Whitby, P. S., \& Hantula, D. (2015). A systematic review of tablet computers and portable media players as speech generating devices for individuals with autism spectrum disorder. Journal of Autism and Developmental Disorders, 45(12). doi:10.1007/s10803-014-2314-4.

Macpherson, K., Charlop, M. H., \& Miltenberger, C. A. (2015). Using Portable Video Modeling Technology to Increase the Compliment Behaviors of Children with Autism During Athletic Group Play. Journal of Autism and Developmental Disorders, 45(12). doi:10.1007/s10803-014-2072-3.

McCleery, J. P. (2015). Comment on technology-based intervention research for individuals on the autism spectrum. Journal of Autism and Developmental Disorders, 45(12). doi:10.1007/ s10803-015-2627-y.

Odom, S. L., Thompson, J. L., Hedges, S., Boyd, B. A., Dykstra, J. R., Duda, M. A., et al. (2015). Technology-aided interventions and instruction for adolescents with autism spectrum disorder. Journal of Autism and Developmental Disorders, 45(12). doi:10.1007/s10803-014-2320-6.

Raine, L. (2014). Three technology revolutions. Pew Research Center: Internet, Science and Tech. http://www.pewinternet. org/three-technology-revolutions/.

Rice, L. M., Wall, C. A., Fogel, A., \& Shic, F. (2015). Computerassisted face processing instruction improves emotion recognition, mentalizing, and social skills in students with ASD. Journal of Autism and Developmental Disorders, 45(7), 2176-2186. doi:10.1007/s10803-015-2380-2.

Scassellati, B., Admoni, H., \& Matarić, M. (2012). Robots for use in autism research. Annual Review of Biomedical Engineering,. doi:10.1146/annurev-bioeng-071811-150036.

Shic, F., Smith, D., Horsburgh, B., Hollander, E., Rehg, J. M., \& Goodwin, M. (2015). Catalysts for change: The role of small 
business funders in the creation and dissemination of innovation. Journal of Autism and Developmental Disorders, 45(12). doi:10. 1007/s10803-015-2636-x.

Smith, M. J., Fleming, M. F., Wright, M. A., Losh, M., Humm, L. B., Olsen, D., \& Bell, M. D. (2015). Brief report: Vocational outcomes for young adults with autism spectrum disorders at six months after virtual reality job interview training. Journal of Autism and Developmental Disorders, 45(10), 3364-3369. doi:10.1007/s10803-015-2470-1.

Spriggs, A. D., Knight, V., \& Sherrow, L. (2015). Talking picture schedules: Embedding video models into visual activity schedules to increase independence for students with ASD. Journal of Autism and Developmental Disorders, 45(12). doi:10.1007/ s10803-014-2315-3.

Stephenson, J., \& Limbrick, L. (2015). A review of the use of touchscreen mobile devices by people with developmental disabilities.
Journal of Autism and Developmental Disorders, 45(12). doi:10. 1007/s10803-013-1878-8.

Wainer, A. L., \& Ingersoll, B. R. (2015). Increasing access to an ASD imitation intervention via a telehealth parent training program. Journal of Autism and Developmental Disorders, 45(12). doi:10. 1007/s10803-014-2186-7.

Warren, Z., Zheng, Z., Das, S., Young, E. M., Swanson, A., Weitlauf, A., \& Sarkar, N. (2015). Brief report: Development of a robotic intervention platform for young children with ASD. Journal of Autism and Developmental Disorders, 45(12). doi:10.1007/ s10803-014-2334-0.

Whyte, E. M., Smyth, J. M., \& Scherf, K. S. (2015). Designing Serious Game Interventions for Individuals with Autism. Journal of Autism and Developmental Disorders, 45(12). doi:10.1007/ s10803-014-2333-1. 